\title{
Sperm competition differentially affects swimming velocity and size of spermatozoa from closely related muroid rodents: head first
}

\author{
Laura Gómez Montoto, María Varea Sánchez, Maximiliano Tourmente, Juan Martín-Coello, \\ Juan José Luque-Larena ${ }^{1}$, Montserrat Gomendio and Eduardo R S Roldan
}

Reproductive Ecology and Biology Group, Museo Nacional de Ciencias Naturales (CSIC), C/Jose Gutierrez Abascal 2, 28006 Madrid, Spain and ${ }^{1}$ Área de Zoología, Departamento de Ciencias Agroforestales, E.T.S. Ingenierías Agrarias, Universidad de Valladolid, Campus La Yutera, 34004 Palencia, Spain

Correspondence should be addressed to E R S Roldan; Email: roldane@mncn.csic.es

M Gomendio and E R S Roldan contributed equally to this work

\begin{abstract}
Sperm competition favours an increase in sperm swimming velocity that maximises the chances that sperm will reach the ova before rival sperm and fertilise. Comparative studies have shown that the increase in sperm swimming speed is associated with an increase in total sperm size. However, it is not known which are the first evolutionary steps that lead to increases in sperm swimming velocity. Using a group of closely related muroid rodents that differ in levels of sperm competition, we here test the hypothesis that subtle changes in sperm design may represent early evolutionary changes that could make sperm swim faster. Our findings show that as sperm competition increases so does sperm swimming speed. Sperm swimming velocity is associated with the size of all sperm components. However, levels of sperm competition are only related to an increase in sperm head area. Such increase is a consequence of an increase in the length of the sperm head, and also of the presence of an apical hook in some of the species studied. These findings suggest that the presence of a hook may modify the sperm head in such a way that would help sperm swim faster and may also be advantageous if sperm with larger heads are better able to attach to the epithelial cells lining the lower isthmus of the oviduct where sperm remain quiescent before the final race to reach the site of fertilisation.
\end{abstract}

Reproduction (2011) 142 819-830

\section{Introduction}

Sperm competition occurs when spermatozoa from more than one male coexist within the female reproductive tract and compete to fertilise the ova (Parker 1970), a widespread phenomenon that has been identified in many taxa such as insects (Parker 1970, Simmons 2001), fishes (Stockley et al. 1997), amphibians (Jennions \& Passmore 1993), birds (Birkhead \& Møller 1992) and mammals (Gomendio et al. 1998). Competition between spermatozoa from rival males has led to increases in testes mass relative to body mass (Harcourt et al. 1981, Gomendio et al. 1998, Simmons 2001, Birkhead et al. 2009), and large numbers of sperm in the ejaculate, a trait that is an important determinant of fertilisation success (Gomendio et al. 1998, 2007).

Increased sperm competition is also associated with faster sperm swimming velocity in cichlid fishes (Fitzpatrick et al. 2009), birds (Lüpold et al. 2009) and mammals (Tourmente et al. 2011a). Because the first spermatozoon to reach the ovum is more likely to engage in fertilisation (Cummins \& Yanagimachi 1982), faster swimming speed is regarded as an adaptive trait. Sperm swimming velocity has been shown to be an important determinant of fertilisation success under both competitive (Birkhead et al. 1999, Gage et al. 2004, Gasparini et al. 2010) and non-competitive scenarios (Froman et al. 1999, Levitan 2000, Malo et al. 2005).

Increases in sperm swimming speed may result from changes in sperm size (Gomendio \& Roldan 1991). This hypothesis has received support from interspecific studies in many taxa (reviewed in Gomendio \& Roldan (2008); and see Tourmente et al. (2011a)), which have revealed positive associations between sperm size and sperm swimming velocity. Furthermore, detailed comparative studies in eutherian mammals have shown that the increase in total sperm size is the result of an increase in the length of all sperm components (sperm head, midpiece and principal piece), as well as an elongation of the sperm head (i.e. increase in head length $(\mathrm{HL}) /$ head 
width (HW) ratio; Tourmente et al. 2011a). Thus, across a wide range of species, all sperm components increase in response to sperm competition because they all contribute in complementary ways to an increase in sperm swimming velocity.

How can sperm velocity be affected by increases in the dimensions of sperm components, or by changes in the proportion between them? A longer flagellum may provide more propelling force (Gomendio \& Roldan 1991), whereas a longer or more voluminous midpiece may accommodate more mitochondria with a resulting increase in the amount of energy generated (Anderson \& Dixson 2002, Anderson et al. 2005, Tourmente et al. 2009). In mammalian sperm, energy can also be generated in the principal piece through glycolysis (Miki et al. 2004) and, thus, an increase in principal piece length may allow for more ATP production. Modifications in the dimensions of the sperm head may also lead to an increase in head elongation (i.e. increase in HL/HW ratio) that could reduce drag and lead to a more efficient propulsion (Malo et al. 2006, Gillies et al. 2009, Tourmente et al. 2011a). Sperm heads may also bear modifications either in the apical or in the basal region, particularly in rodents, in which hooks or post-nuclear appendices have been described, and which may be related to more efficient swimming (reviewed in Roldan et al. (1992)). Swimming velocity may also increase as a result of changes in the proportions between sperm components. A proportionately longer flagellum (in relation to sperm head size) may better overcome the drag of the sperm head (Humphries et al. 2008, Tourmente et al. 2011a).

However, studies on closely related species and intraspecific comparisons have not always revealed a clear association between sperm swimming velocity and sperm size (Gage et al. 1998, 2002, LaMunyon \& Ward 1998). Since closely related species, or males from the same species, show a much smaller degree of variation, the relationships between sperm swimming speed and size may only be uncovered when both dimensions and velocity are examined in the same sperm cells rather than each parameter being quantified in different subsamples from the same male (Fitzpatrick et al. 2010). Besides methodological issues, different hypotheses have been proposed to explain which are the first evolutionary steps that lead to early increases in sperm swimming velocity. An intraspecific study on red deer showed that an elongation of the sperm head was associated with an increase in sperm swimming speed, suggesting that elongated sperm heads experience a reduction in drag and make sperm more hydrodynamically efficient (Malo et al. 2006). Alternatively, a comparative study on a closely related group of cichlid fish found an evolutionary disassociation between increases in sperm swimming speed in response to sperm competition and the size of the sperm, and postulated that the first steps may involve increases in energy production which precede any changes in sperm dimensions (Fitzpatrick et al. 2009). This latter hypothesis may only apply to external fertilisers, since they rely on endogenous energy sources alone, and it may differ from that in internal fertilisers that have energy sources available during transit along the male and female reproductive tracts. With the available evidence it is not possible to disentangle these two hypotheses, since few studies have measured changes in the dimensions of sperm components or in the shape of the sperm head and no study has measured ATP production in a group of closely related species.

Therefore, we investigated the impact of sperm competition on sperm swimming velocity and sperm dimensions in muroid rodents. This group of phylogenetically close species exhibits a wide range of variation in relative testes mass (Gómez Montoto et al. 2011) and, thus, considerable differences in levels of sperm competition (Soulsbury 2010), and also has a wide range of sperm sizes (Cummins \& Woodall 1985) and sperm morphologies (Roldan et al. 1992). These taxa represent an ideal system to understand the impact of sperm competition on sperm velocity and sperm design, and explore possible associations between both. We aimed to identify early evolutionary signals examining how are sperm competition levels among these closely related species associated with changes in sperm swimming velocity, and size and proportions of sperm components, with special attention to changes in the design of the sperm head.

\section{Results}

\section{Body and testes mass in muroid rodents}

In this study, variation in both body and testes mass was high among muroid species (body mass range $=14.49$ $217.67 \mathrm{~g}$, coefficient of variation $(\mathrm{CV})=128.4 \%$ and testes mass range $=0.082-2.238 \mathrm{~g}, \mathrm{CV}=117.7 \%$ ). As a result, relative testes mass also showed a great deal of variation (range $=0.194-2.266, \mathrm{CV}=69.9 \%$ ). The difference in testes mass between the species with lowest and highest values was $\sim 27$-fold, although there was only a $\sim 15$-fold difference in body mass among them. Therefore, differences in testes mass greatly exceeded differences in organ size that could be explained by changes in body size (Gomendio et al. 1998). This suggests that, despite being phylogenetically close, there are major differences in levels of sperm competition among these species.

\section{Sperm competition and sperm velocity}

Sperm velocity parameters had a normal distribution and substantial differences were found in average values among species: curvilinear velocity $(\mathrm{VCL})$ range $=77.8-$ $196.0 \mu \mathrm{m} / \mathrm{s}(\mathrm{CV}=27.4 \%)$; average path velocity (VAP) 
Table 1 Factor loadings of the six sperm velocity components obtained by means of a principal component analysis.

\begin{tabular}{lcc}
\hline $\begin{array}{l}\text { Sperm velocity } \\
\text { components }\end{array}$ & $\begin{array}{c}\text { Factor score 1 } \\
\text { Factor loadings }\end{array}$ & $\begin{array}{c}\text { Factor score 2 } \\
\text { Factor loadings }\end{array}$ \\
\hline VCL & 0.998 & -0.016 \\
VSL & 0.957 & 0.253 \\
VAP & 0.986 & 0.113 \\
LIN & 0.040 & 0.896 \\
ALH & 0.135 & 0.553 \\
BCF & 0.804 & -0.558 \\
Eigenvalue & 3.551 & 1.497 \\
Variance explained $(\%)$ & 59.2 & 24.9 \\
\hline
\end{tabular}

Factors were unrotated. VCL, curvilinear velocity; VSL, straight-line velocity; VAP, average path velocity; LIN, linearity; ALH, amplitude of lateral head displacement and BCF, beat cross frequency.

range $=63.0-170.9 \mu \mathrm{m} / \mathrm{s} \quad(C V=29.2 \%)$; straight-line velocity (VSL) range $=50.9-152.4 \mu \mathrm{m} / \mathrm{s}(\mathrm{CV}=29.6 \%)$; linearity $(\mathrm{LIN})$ range $=55.05-86.0 \%(\mathrm{CV}=13 \%)$; amplitude of lateral head displacement $(\mathrm{ALH})$ range $=1.7-$ $4.1 \mu \mathrm{m} / \mathrm{s}(\mathrm{CV}=21.3 \%)$; and beat cross frequency (BCF) range $=7.8-20.7 \mathrm{~Hz} \quad(\mathrm{CV}=32.1 \%)$. Maximum $\mathrm{VCL}$ $($ VCLmax; range $=155.0-356.5 \mu \mathrm{m} / \mathrm{s} ; \mathrm{CV}=29.4 \%$ ) and maximum VSL (VSLmax; range $=134.6-315.3 \mu \mathrm{m} / \mathrm{s}$; $\mathrm{CV}=31.9 \%$ ) achieved by spermatozoa from different species also varied widely.

Sperm velocity parameters examined together in a principal component analysis (PCA), yielded an 'overall sperm velocity' variable with two factor scores (1 and 2) that explained $84 \%$ of the variance (Table 1 ).

Phylogenetically controlled multiple regression analyses showed a significant positive association between testes mass corrected for body mass (thereafter, relative testes mass) and VCL, VSL, VAP, LIN and VSLmax (Table 2). There was also a significant association with the 'overall sperm velocity' parameter and this association was stronger than that seen with any individual velocity descriptor (Table 2 and Fig. 1).

\section{Sperm dimensions}

To understand which sperm components may affect swimming velocity we first quantified dimensions of the different sperm structures. Sperm dimensions followed a normal distribution and none was related to body mass. Considerable variation in sperm dimensions was recorded among species: $\mathrm{HL}$ range $=4.75-9.25 \mu \mathrm{m}(\mathrm{CV}=19.5 \%)$; $\mathrm{HW}$ range $=3.00-5.32 \mu \mathrm{m}(\mathrm{CV}=17.9 \%)$; head area $(\mathrm{HA})$ range $=11.96-35.47 \mu \mathrm{m}^{2}(\mathrm{CV}=30.5 \%)$; midpiece length (MPL) range $=14.84-26.63 \mu \mathrm{m}(\mathrm{CV}=14.6 \%)$; principal plus terminal piece length range $(\mathrm{PPL}+\mathrm{TPL})=42.90$ $94.00 \mu \mathrm{m} \quad(\mathrm{CV}=23.1 \%)$; total flagellum length (TFL) range $=57.73-119.49 \mu \mathrm{m}(\mathrm{CV}=20.5 \%)$ and total sperm length $(\mathrm{TSL})$ range $=62.69-126.15 \mu \mathrm{m} \quad(\mathrm{CV}=19.7 \%)$. Three of the species had round or oval sperm heads, without a hook, whereas the remaining eight species had a hook in the apical region of the head (Fig. 2).

Because of the variation observed in dimensions of sperm components, we next examined possible relationships between these measures by means of phylogenetically controlled analyses to understand if increases in head size were accompanied by increases in flagellum size (Fig. 3 and Table 3). There was a positive association between length and width of the sperm head among species, and between length of the sperm head and lengths of the midpiece, the PPL + TPL and TFL. Likewise, there was a positive relationship between MPL and PPL + TPL. HA was also positively related to lengths of the midpiece, the PPL + TPL and TFL (Fig. 3 and Table 3). Thus, it was clear that increases in one sperm component were accompanied by an increase in other sperm structures.

\section{Sperm velocity and sperm dimensions}

In phylogenetically controlled analyses, VCL showed a positive association with all sperm dimensions (Table 4).

Table 2 Phylogenetically controlled multiple regression analyses of sperm velocity components in relation to body mass and testes mass.

\begin{tabular}{|c|c|c|c|c|c|c|c|c|}
\hline Dependent variables & Predictors & Adjusted $R^{2}$ & Slope & $\boldsymbol{F}$ & $\boldsymbol{P}$ & Lambda $(\lambda)$ & Effect size $(r)$ & Effect size CLs \\
\hline \multirow[t]{2}{*}{ VCL } & Body mass & 0.440 & -37.21 & 1.66 & 0.2337 & $0.4589^{+,+}$ & 0.41 & $-0.25-1.13$ \\
\hline & Testes mass & & 82.13 & 8.19 & 0.0211 & & 0.71 & $0.20-1.58$ \\
\hline \multirow[t]{2}{*}{ VSL } & Body mass & 0.589 & -60.45 & 0.23 & 0.6432 & $0.4832^{+,+}$ & 0.17 & $-0.52-0.86$ \\
\hline & Testes mass & & 82.31 & 16.10 & 0.0039 & & 0.81 & $0.45-1.84$ \\
\hline \multirow[t]{2}{*}{ VAP } & Body mass & 0.536 & -61.76 & 0.24 & 0.6351 & $0.6238^{+,+}$ & 0.17 & $-0.52-0.86$ \\
\hline & Testes mass & & 88.98 & 13.32 & 0.0065 & & 0.79 & $0.38-1.76$ \\
\hline \multirow{2}{*}{ LIN } & Body mass & 0.596 & -0.25 & 10.54 & 0.0118 & $<0.0001^{+, *}$ & 0.75 & $0.29-1.67$ \\
\hline & Testes mass & & 0.13 & 6.24 & 0.0371 & & 0.66 & $0.10-1.49$ \\
\hline \multirow[t]{2}{*}{ VSLmax } & Body mass & 0.622 & -1.66 & 8.19 & 0.0211 & $0.6366^{+,+}$ & 0.71 & $0.20-1.58$ \\
\hline & Testes mass & & 129.17 & 10.26 & 0.0125 & & 0.75 & $0.28-1.66$ \\
\hline \multirow[t]{2}{*}{ Overall sperm velocity } & Body mass & 0.678 & -1.56 & 0.89 & 0.3737 & $<0.0001^{+, *}$ & 0.32 & $-0.36-1.02$ \\
\hline & Testes mass & & 1.53 & 22.15 & 0.0015 & & 0.86 & $0.59-1.97$ \\
\hline
\end{tabular}

All tests were conducted with $8 \mathrm{df}$. The superscripts following $\lambda$ value indicate significance levels $\left({ }^{*} P<0.05 ;{ }^{+} \mathrm{NS}\right)$ in a likelihood ratio tests against models with $\lambda=0$ (first position) and $\lambda=1$ (second position). The effect size $r$ calculated from the $F$ values and its non-central $95 \%$ confidence limits (CLs) are presented. Confidence intervals excluding 0 indicate statistically significant relationships. The $P$ values and CLs that indicate statistical significance are shown in bold. VCL, curvilinear velocity; VSL, straight-line velocity; VAP, average path velocity; LIN, linearity and VSLmax, maximal straight-line velocity. 


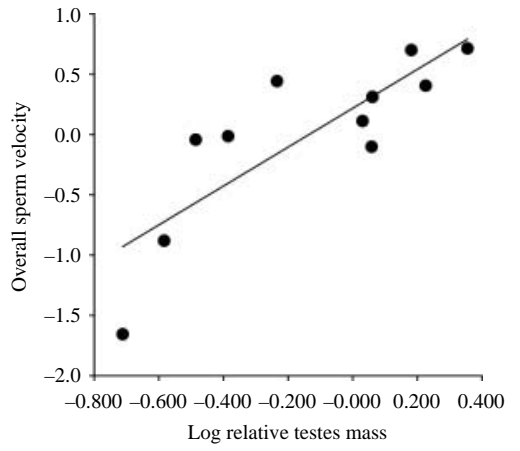

Figure 1 Relationship between relative testes mass and overall sperm velocity in muroid species. Statistical significance of relationship is given in Table 2.

Furthermore, VSL and VAP were also positively associated with sperm head dimensions and with MPL (Table 4). Finally, the PCA-derived overall sperm velocity parameter was positively associated with the dimensions of several sperm components (Table 5), namely $\mathrm{HL}, \mathrm{HA}$, MPL and TSL (Fig. 4), with an association that was marginally significant with TFL. Altogether, head parameters (length and area) had the strongest associations with overall sperm velocity or with individual velocity descriptors. It was observed that species with slower velocities were those that had sperm heads without a hook and smaller HA.

Possible associations between sperm velocity descriptors and proportions between dimensions of sperm components were also examined. Sperm elongation (both $\mathrm{HL} / \mathrm{HW}$ and $(\mathrm{HL}-\mathrm{HW}) /(\mathrm{HL}+\mathrm{HW})$ ) was significantly associated with VCLmax and with other velocity parameters (LIN and BCF) when phylogenetically controlled analyses were carried out.

\section{Sperm competition and sperm dimensions}

Because there was a very strong association between sperm competition levels and sperm velocity and, in turn, between sperm velocity and sperm dimensions (especially dimensions of the sperm head), we searched for direct associations between sperm competition levels and the dimensions and proportions of the different sperm components.

The results of the generalised least squares (GLS) analysis revealed a significant and positive association between relative testes mass and $\mathrm{HA}\left(r^{2}=0.384, F=8.19\right.$ and $P=0.0211$; Fig. 5). Dimensions of the other sperm components were not associated with relative testes mass. The proportions between sperm components were also not associated with relative testes mass.

\section{Discussion}

We studied a group of closely related species in an effort to understand which may be the first evolutionary changes in sperm design that lead to an increase in sperm swimming velocity under sperm competition. The results of this study show that high levels of sperm competition in muroid rodents relate strongly to increases in sperm swimming velocity which are, in turn, strongly associated with total length of spermatozoa, as well as with dimensions of different sperm components. However, our findings reveal that levels of sperm competition are only directly associated with the dimensions of sperm heads in these species. Thus, it appears that early evolutionary changes brought about by sperm competition among phylogenetically close species may relate to modifications in the design of the sperm head and that this could be an important driving force affecting sperm performance. The question that remains to be answered is what adaptive value may underlie such increases in sperm head dimensions that appear to precede increases in other sperm components, and that are selected in response to sperm competition.

High levels of sperm competition were found to be associated, in phylogenetically controlled analyses, to fast swimming velocity. The association was clear for several individual descriptors of swimming velocity (i.e. average values of each of the different parameters used to describe sperm swimming). Maximum values of straightline velocities achieved by spermatozoa from each of the different species were also significantly associated with levels of sperm competition, an important finding given that the fastest sperm is likely to win the race to fertilise ova (Cummins \& Yanagimachi 1982). Furthermore, a

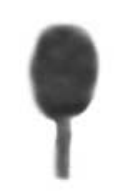

(a)

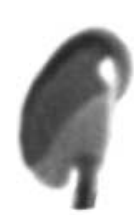

(e)

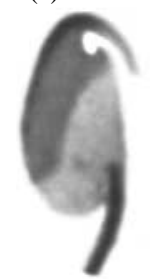

(i)

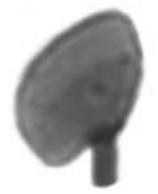

(b)

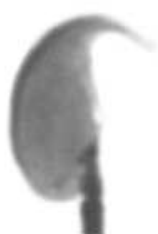

(f)

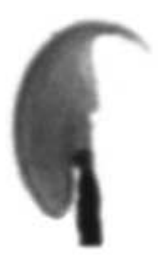

(j)

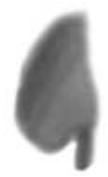

(c)

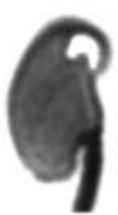

(g)

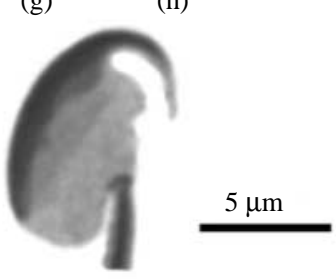

(k) (d)
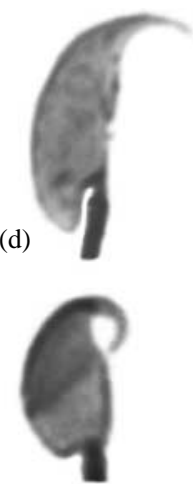

(h)
Figure 2 Sperm head morphology in muroid species. (a) Microtus duodecimcostatus, (b) Microtus cabrerae, (c) Microtus lusitanicus, (d) Mus musculus, (e) Microtus arvalis, (f) Mus spretus, (g) Arvicola sapidus, (h) Clethrionomys glareolus, (i) Chionomys nivalis, (j) Mus spicilegus and (k) Apodemus sylvaticus. 
A
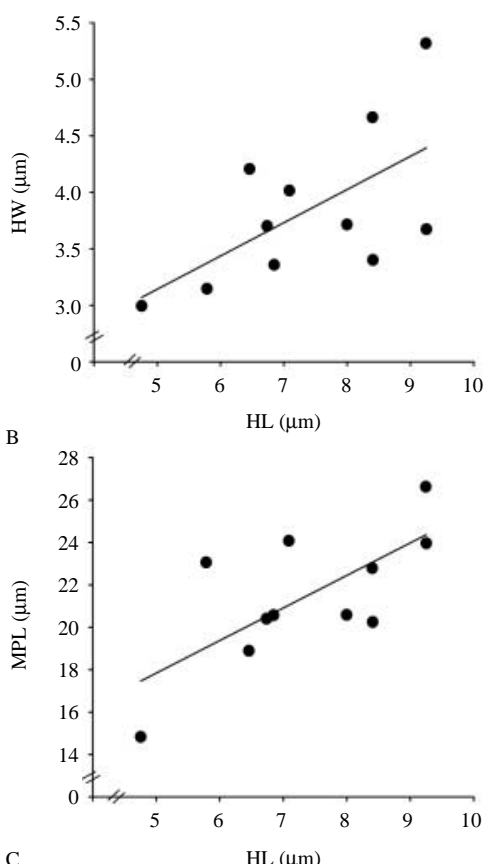

C

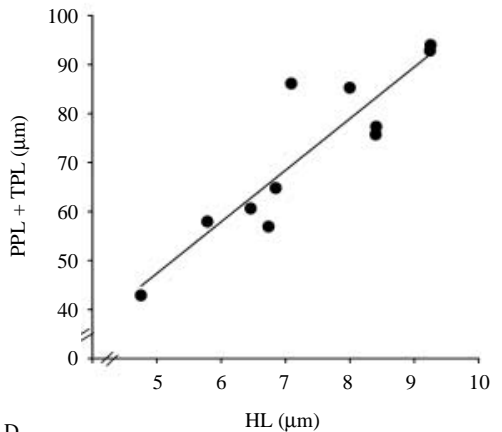

D

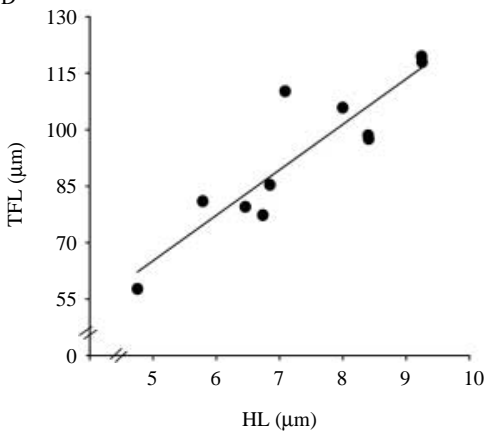

E
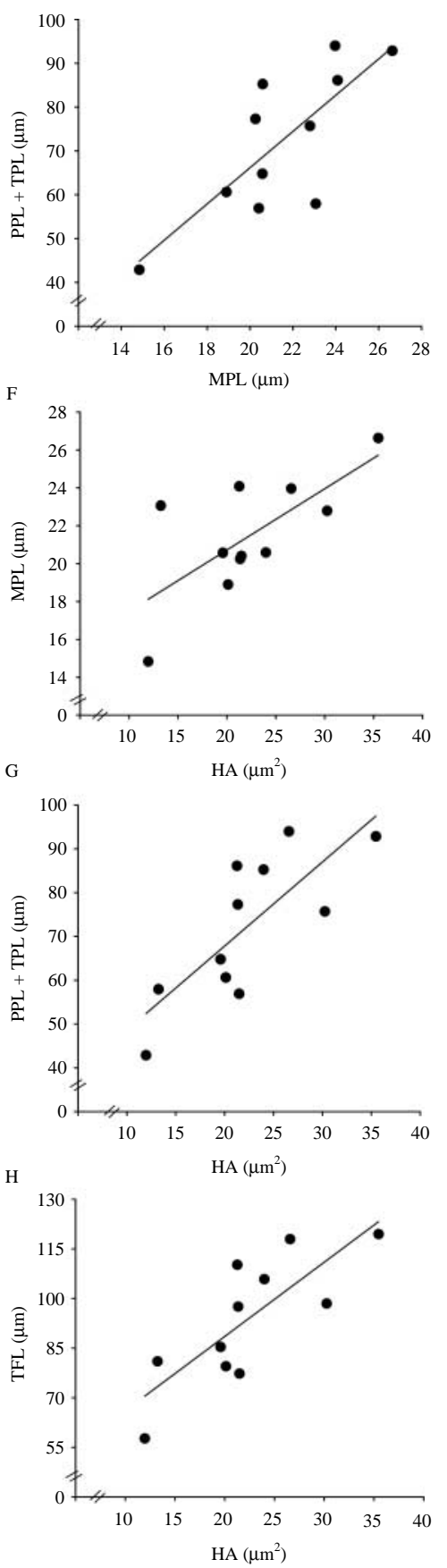

Figure 3 Relationships between dimensions of different sperm components in muroid rodents. Relationship between $(A)$ head length $(\mathrm{HL})$ and head width $(\mathrm{HW})$, (B) $\mathrm{HL}$ and midpiece length (MPL), (C) $\mathrm{HL}$ and principal plus terminal piece length (PPL $+\mathrm{TPL}),(\mathrm{D}) \mathrm{HL}$ and total flagellum length (TFL), (E) MPL and PPL + TPL, (F) head area $(\mathrm{HA})$ and $M P L,(G) H A$ and $P P L+T P L$, and $(H) H A$ and TFL. Statistical significance of relationships is given in Table 3.
PCA-derived 'overall swimming velocity' global value was also positively related to levels of sperm competition, with a level of significance that was much higher than that seen with individual sperm velocity descriptors. These results thus lend further support to a recent comparative analysis in mammals, based on data gathered from the literature (Tourmente et al. 2011a), and studies on cichlid fish (Fitzpatrick et al. 2009) and birds (Lüpold et al. 2009) that showed that sperm competition selects for faster swimming sperm.
Sperm motility is important at different stages in the life of sperm cells. Spermatozoa acquire the capacity to move during their transit along the epididymis where changes in sperm structures (e.g. compaction of the sperm head) and reorganisation of membrane proteins and lipids may also take place (Cooper 2007). Upon contact with secretions from the male accessory glands or fluids from the female reproductive tract, spermatozoa become activated (i.e. express the capacity to swim). Forward motility is important to negotiate barriers in the 
Table 3 Phylogenetically controlled regression analyses of relationships between sperm dimensions.

\begin{tabular}{|c|c|c|c|c|c|c|c|c|}
\hline $\begin{array}{l}\text { Dependent } \\
\text { variables }\end{array}$ & Predictors & Adjusted $R^{2}$ & Slope & $F$ & $\boldsymbol{P}$ & Lambda $(\lambda)$ & $\begin{array}{c}\text { Effect } \\
\text { size }(r)\end{array}$ & $\begin{array}{c}\text { Effect } \\
\text { size CLs }\end{array}$ \\
\hline $\mathrm{HW}$ & $\mathrm{HL}$ & 0.349 & 0.67 & 6.35 & 0.0327 & $0.9999^{\dagger,+}$ & 0.64 & $0.07-1.46$ \\
\hline \multirow[t]{2}{*}{ MPL } & $\mathrm{HL}$ & 0.446 & 0.56 & 9.05 & 0.0147 & $<0.0001^{+, *}$ & 0.71 & $0.19-1.58$ \\
\hline & $\mathrm{HA}$ & 0.473 & 0.36 & 9.98 & 0.0115 & $<0.0001^{+, *}$ & 0.72 & $0.22-1.61$ \\
\hline \multirow[t]{3}{*}{$P P L+T P L$} & $\mathrm{HL}$ & 0.635 & 1.05 & 18.39 & 0.0020 & $0.9999^{t,+}$ & 0.82 & $0.46-1.85$ \\
\hline & $\mathrm{HA}$ & 0.385 & 0.47 & 7.26 & 0.0246 & $0.7289^{t,+}$ & 0.67 & $0.11-1.50$ \\
\hline & MPL & 0.651 & 0.89 & 19.69 & 0.0016 & $0.9999^{*,+}$ & 0.83 & $0.49-1.88$ \\
\hline \multirow[t]{2}{*}{ TFL } & $\mathrm{HL}$ & 0.712 & 0.96 & 25.71 & 0.0007 & $<0.0001^{+,+}$ & 0.86 & $0.60-1.99$ \\
\hline & $\mathrm{HA}$ & 0.434 & 0.45 & 8.66 & 0.0164 & $0.4103^{t, t}$ & 0.70 & $0.17-1.56$ \\
\hline
\end{tabular}

All tests were conducted with $9 \mathrm{df}$. The superscripts following $\lambda$ value indicate significance levels $\left({ }^{*} P<0.05 ;{ }^{\dagger} \mathrm{NS}\right)$ in likelihood ratio tests against models with $\lambda=0$ (first position) and $\lambda=1$ (second position). The effect size $r$ calculated from the $F$ values and its non-central $95 \%$ confidence limits $(\mathrm{CLs})$ are presented. Confidence intervals excluding 0 indicate statistically significant relationships. The $P$ values and CLs that indicate statistical significance are shown in bold. $\mathrm{HL}$, head length; HW, head width; $\mathrm{HA}$, head area; MPL, midpiece length; PPL+TPL, principal plus terminal piece length and TFL, total flagellum length.

female tract, such as the cervix or the uterotubal junction and, after a period of quiescence attending ovulation, to dislodge from the so-called reservoirs in the female tract (i.e. the lower isthmus of the oviduct in mammals) and move towards the site of fertilisation (Suarez 1998, 2008). Several ill-defined changes taking place during the so-called capacitation process modify the sperm swimming pattern and spermatozoa develop what is described as hyperactivated motility (Florman \& Ducibella 2006). Although the proportion of sperm showing forward progression (i.e. the proportion of motile sperm) is an essential determinant of fertility, since a higher percentage of motile sperm would increase the chances of fertilisation, it is the velocity at which sperm swim that appears to be a key factor in the race to fertilise ova (Malo et al. 2005), because it would allow sperm to reach the site of fertilisation first, and would ensure penetration of ovum vestments.

To understand how faster swimming speeds are achieved, it is important to consider various possibilities that may result in enhancements of sperm velocity: a) sperm design, i.e. size of sperm components, the proportion between the size of these components and the shape of the sperm head, b) metabolic function of spermatozoa in relation to generation and use of energy sources, and, perhaps c) signalling processes that convey

Table 4 Phylogenetically controlled regression analyses of sperm velocity components in relation to sperm dimensions.

\begin{tabular}{|c|c|c|c|c|c|c|c|c|}
\hline $\begin{array}{l}\text { Dependent } \\
\text { variables }\end{array}$ & Predictors & Adjusted $\boldsymbol{R}^{2}$ & Slope & $\boldsymbol{F}$ & $\boldsymbol{P}$ & Lambda $(\lambda)$ & Effect size $(r)$ & Effect size CLs \\
\hline \multirow[t]{8}{*}{$\mathrm{VCL}$} & $\mathrm{HL}$ & 0.433 & 1.35 & 8.63 & 0.0166 & $0.9999 *,+$ & 0.70 & $0.17-1.56$ \\
\hline & $\mathrm{HW}$ & 0.415 & 1.08 & 8.10 & 0.0192 & $0.0791^{\dagger, *}$ & 0.69 & $0.15-1.54$ \\
\hline & $\mathrm{HA}$ & 0.418 & 0.71 & 8.17 & 0.0188 & $0.6760^{\dagger, t}$ & 0.69 & $0.15-1.54$ \\
\hline & Head elongation & 0.012 & -0.43 & 1.12 & 0.3180 & $<0.0001^{t,+}$ & 0.33 & $-0.35-1.04$ \\
\hline & MPL & 0.415 & 1.25 & 8.09 & 0.0192 & $0.6739^{\dagger, \dagger}$ & 0.69 & $0.15-1.54$ \\
\hline & $P P L+T P L$ & 0.215 & 0.81 & 3.74 & 0.0849 & $0.9464^{\dagger, \dagger}$ & 0.54 & $-0.09-1.29$ \\
\hline & TFL & 0.318 & 0.98 & 5.65 & 0.0413 & $0.9999^{+, \dagger}$ & 0.62 & 0.03-1.42 \\
\hline & TSL & 0.340 & 1.06 & 6.16 & 0.0349 & $0.9999^{\dagger, t}$ & 0.64 & $0.06-1.45$ \\
\hline \multirow[t]{8}{*}{ VSL } & $\mathrm{HL}$ & 0.347 & 1.23 & 6.32 & 0.0331 & $0.6658^{t, t}$ & 0.64 & $0.07-1.45$ \\
\hline & HW & 0.363 & 1.09 & 6.69 & 0.0293 & $<0.0001^{+, *}$ & 0.65 & $0.09-1.47$ \\
\hline & $\mathrm{HA}$ & 0.368 & 0.68 & 6.83 & 0.0281 & $0.0871^{\dagger, *}$ & 0.66 & $0.09-1.48$ \\
\hline & Head elongation & -0.102 & -0.13 & 0.07 & 0.7895 & $<0.0001^{+,+}$ & 0.09 & $-0.60-0.78$ \\
\hline & MPL & 0.402 & 1.38 & 7.72 & 0.0214 & $<0.0001^{+, *}$ & 0.68 & $0.13-1.52$ \\
\hline & $P P L+T P L$ & 0.039 & 0.47 & 1.41 & 0.2652 & $<0.0001^{+,+}$ & 0.37 & $-0.31-1.08$ \\
\hline & TFL & 0.091 & 0.62 & 2.00 & 0.1904 & $<0.0001^{+,+}$ & 0.43 & $-0.24-1.15$ \\
\hline & TSL & 0.106 & 0.68 & 2.19 & 0.1729 & $<0.0001^{+,+}$ & 0.44 & $-0.22-1.17$ \\
\hline \multirow[t]{8}{*}{ VAP } & $\mathrm{HL}$ & 0.311 & 1.30 & 5.51 & 0.0435 & $0.8434^{+,+}$ & 0.62 & $0.02-1.41$ \\
\hline & HW & 0.347 & 1.07 & 6.33 & 0.0330 & $<0.0001^{+, *}$ & 0.64 & 0.07-1.45 \\
\hline & $\mathrm{HA}$ & 0.337 & 0.69 & 6.09 & 0.0356 & $0.3995^{\dagger, t}$ & 0.63 & $0.06-1.44$ \\
\hline & Head elongation & -0.049 & -0.32 & 0.52 & 0.4872 & $<0.0001^{\dagger,+}$ & 0.23 & $-0.45-0.93$ \\
\hline & MPL & 0.359 & 1.34 & 6.62 & 0.0300 & $0.2551^{+,+}$ & 0.65 & 0.08-1.47 \\
\hline & $P P L+T P L$ & 0.025 & 0.54 & 1.26 & 0.2912 & $0.4144^{\dagger, t}$ & 0.35 & $-0.33-1.06$ \\
\hline & TFL & 0.099 & 0.75 & 2.11 & 0.1802 & $0.5407^{\dagger, \dagger}$ & 0.43 & $-0.22-1.16$ \\
\hline & TSL & 0.125 & 0.85 & 2.43 & 0.1531 & $0.5778^{\dagger, t}$ & 0.46 & $-0.19-1.19$ \\
\hline
\end{tabular}

All tests were conducted with $9 \mathrm{df}$. The superscripts following $\lambda$ value indicate significance levels $\left({ }^{*} P<0.05 ;{ }^{+} \mathrm{NS}\right)$ in likelihood ratio tests against models with $\lambda=0$ (first position) and $\lambda=1$ (second position). The effect size $r$ calculated from the $F$ values and its non-central $95 \%$ confidence limits (CLs) are presented. Confidence intervals excluding 0 indicate statistically significant relationships. The $P$ values and CLs that indicate statistical significance are shown in bold. A measure of sperm head elongation was calculated as $(\mathrm{HL}-\mathrm{HW}) /(\mathrm{HL}+\mathrm{HW})$. $\mathrm{HL}$, head length; HW, head width; $\mathrm{HA}$, head area; MPL, midpiece length; PPL + TPL, principal plus terminal piece length; TFL, total flagellum length and TSL, total sperm length. 
Table 5 Phylogenetically controlled regression analyses of sperm velocity in relation to sperm dimensions.

\begin{tabular}{llccrrrrr}
\hline $\begin{array}{l}\text { Dependent } \\
\text { variables }\end{array}$ & Predictors & Adjusted $\boldsymbol{R}^{\mathbf{2}}$ & Slope & $\boldsymbol{F}$ & $\boldsymbol{P}$ & Lambda $(\lambda)$ & $\begin{array}{r}\text { Effect } \\
\text { size }(r)\end{array}$ & $\begin{array}{c}\text { Effect } \\
\text { size CLs }\end{array}$ \\
\hline Overall sperm & HL & 0.512 & 5.70 & 11.51 & $\mathbf{0 . 0 0 8 0}$ & $<0.0001^{+, *}$ & 0.75 & $\mathbf{0 . 2 8 - 1 . 6 6}$ \\
velocity & HW & 0.197 & 4.16 & 3.46 & 0.0959 & $<0.0001^{+, *}$ & 0.53 & $-0.11-1.28$ \\
& HA & 0.498 & 3.49 & 10.93 & $\mathbf{0 . 0 0 9 1}$ & $<0.0001^{+, *}$ & 0.74 & $\mathbf{0 . 2 6 - 1 . 6 4}$ \\
& Head elongation & 0.038 & 2.38 & 1.39 & 0.2681 & $<0.0001^{+,+}$ & 0.36 & $-0.31-1.08$ \\
& MPL & 0.414 & 6.59 & 8.06 & $\mathbf{0 . 0 1 9 4}$ & $<0.0001^{+, *}$ & 0.69 & $\mathbf{0 . 1 5 - 1 . 5 3}$ \\
& PPL+TPL & 0.229 & 3.36 & 3.99 & 0.0775 & $<0.0001^{+, *}$ & 0.55 & $-0.07-1.32$ \\
& TFL & 0.276 & 4.04 & 4.82 & 0.0558 & $<0.0001^{+, *}$ & 0.59 & $-0.01-1.37$ \\
& TSL & 0.299 & 4.37 & 5.27 & $\mathbf{0 . 0 4 7 4}$ & $<0.0001^{+, *}$ & 0.61 & $\mathbf{0 . 0 1 - 1 . 4 0}$ \\
\hline
\end{tabular}

All tests were conducted with $9 \mathrm{df}$. The superscripts following $\lambda$ value indicate significance levels $\left({ }^{*} P<0.05 ;{ }^{+} \mathrm{NS}\right)$ in likelihood ratio tests against models with $\lambda=0$ (first position) and $\lambda=1$ (second position). The effect size $r$ calculated from the $F$ values and its non-central $95 \%$ confidence limits (CLs) are presented. Confidence intervals excluding 0 indicate statistically significant relationships. The $P$ values and CLs that indicate statistical significance are shown in bold. The 'overall sperm velocity' parameter was obtained by means of a principal component analysis to reduce potentially correlated components of velocity to a single variable that would summarise the original information (Table 1). A measure of sperm head elongation was calculated as follows: $(\mathrm{HL}-\mathrm{HW}) /(\mathrm{HL}+\mathrm{HW})$. $\mathrm{HL}$, head length; $\mathrm{HW}$, head width; $\mathrm{HA}$, head area; $M P L$, midpiece length; $\mathrm{PPL}+\mathrm{TPL}$, principal plus terminal piece length; TFL, total flagellum length and TSL, total sperm length.

extracellular messages (i.e. chemotactic signals from the ovum) or serve to transmit intracellular signals at different stages in the life of the sperm cell. Species that rely on internal fertilisation (such as mammals) may experience scenarios that differ from those in species that broadcast gametes and engage in external fertilisation. The latter rely exclusively on endogenous sources of energy, while internal fertilisers have exogenous energy sources available during transit along the male and female reproductive tracts.

In this study, we examined whether the enhanced sperm swimming velocity associated with sperm competition was related to differences in sperm design. We found that there were strong positive relationships between dimensions of various sperm components and velocity descriptors as well as with overall sperm velocity; the strongest relations were seen with $\mathrm{HL}$ and HA. There was also a positive association between TSL and overall sperm velocity. These findings give additional support to the hypothesis that longer sperm swim faster (Gomendio \& Roldan 1991, 2008).

Longer spermatozoa would be selected in response to sperm competition (Gomendio \& Roldan 1991) and, indeed, current evidence supports this hypothesis (reviewed in Gomendio \& Roldan (2008); and see Breed \& Taylor (2000) and Tourmente et al. (2009, $2011 a, 2011 b)$ ). The increase in TSL could occur as a result of increases in the dimensions of individual sperm components (Gomendio et al. 2011, Tourmente et al. $2011 a, 2011 b$ ) but it is not known if, under the influence
A
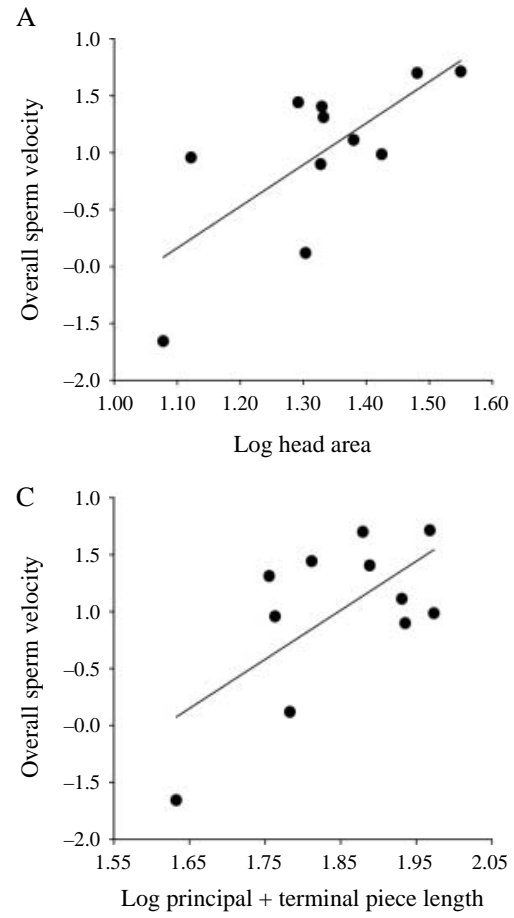

www.reproduction-online.org
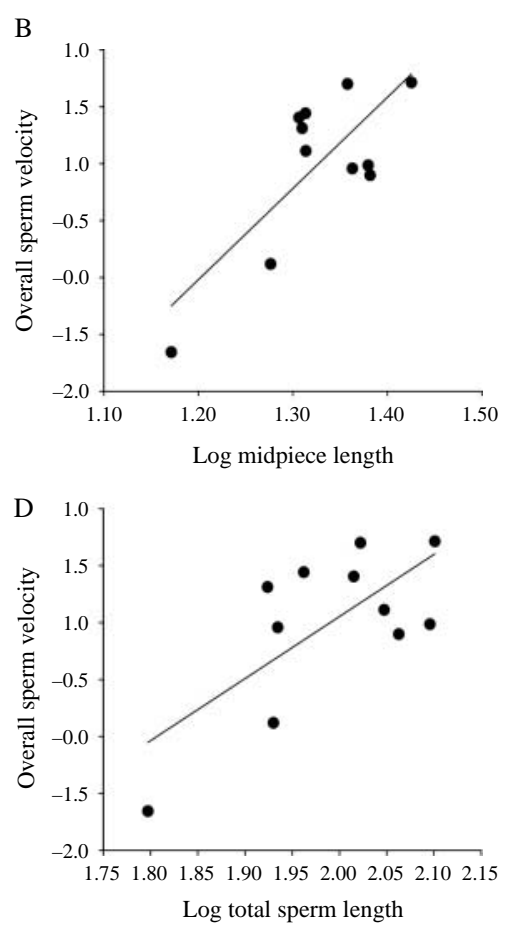

Figure 4 Relationships between sperm dimensions and overall sperm velocity in muroid rodents. (A) Head area, (B) midpiece length, (C) principal plus terminal piece length and (D) total sperm length. Statistical significance of relationships is shown in Table 5 . 


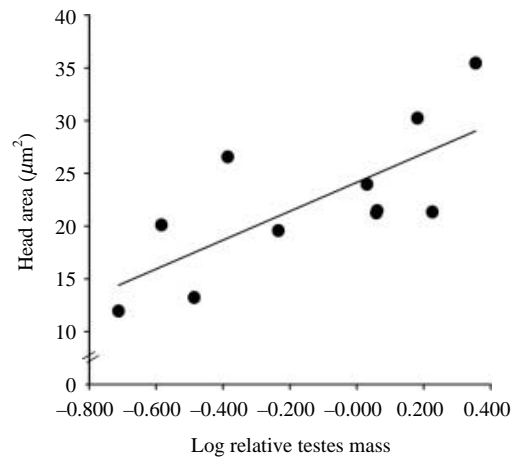

Figure 5 Relationship between relative testes mass and head area in muroid rodents. Statistical significance of relationship is given in the text.

of sperm competition, some sperm components may respond earlier than others to this selective force. Our results revealed positive associations between different sperm components underscoring that, in general terms, sperm increase in size through a concomitant increase in the size of its structures (or, in other words, that some balance exists between the length of different sperm components); this finding agrees with previous studies of comparative spermatology (Roldan et al. 1992, Cassinello et al. 1998, Gage 1998, Ding et al. 2010). However, among our closely related rodent species sperm competition was positively associated with sperm $\mathrm{HA}$, but not with other sperm dimensions (or ratios). Thus, only one sperm component (the size of the sperm head) appears to be responding to sperm competition when a closely related group of species is examined. This observation has two main implications.

First, there is a clear effect of sperm competition on sperm design among closely related muroid species, in contrast to the situation found in cichlid fishes where it has been proposed that the earliest response to an increase in sperm competition levels is an increase in sperm swimming velocity without changes in sperm dimensions (Fitzpatrick et al. 2009). This discrepancy may relate to differences in fertilisation mode (internal in rodents, external in cichlid fishes) and this, in turn, may relate to differences in energy sources available for sperm motility. It has been argued that, in the absence of clear differences in TSL, cichlid fishes may enhance sperm velocity as a result of increases in ATP levels in spermatozoa (Fitzpatrick et al. 2009). Perhaps, fishes rely only on internal ATP reserves (or better use of such reserves). In rodents (as in other mammals), because sperm reside in the female tract for long periods of time, substrates are available for continuous energy production so it may be advantageous for mammals to respond early by modifying sperm design. In any case, it is also possible that cichlid fishes may also respond to sperm competition with subtle modifications in certain sperm components but that such changes may have gone undetected because TSL was the only measure examined (Fitzpatrick et al. 2009).
Among these closely related species of muroid rodents larger sperm heads seen in response to sperm competition were due to increases in sperm HA and this, in turn, was the sperm dimension (together with $\mathrm{HL}$ ) that showed the strongest relation with velocity parameters and overall swimming velocity. Changes in head dimensions may affect hydrodynamic resistance, therefore resulting in a more hydrodynamically efficient sperm design (Malo et al. 2006, Gillies et al. 2009). Furthermore, the increase in sperm HA is associated with the appearance of a hook. Thus, species with smaller HA had no hook, while species with larger HA had an apical hook.

Several roles have been recognised for the hook (see Roldan et al. (1992)) with improvements in sperm motility being a prominent one because the presence of the hook could result in a swimming pattern suitable for the convoluted shape of the rodent female tract or the fluids encountered in the female tract. Based on studies in the wood mouse, Apodemus sylvaticus, it has also been argued that hooks may serve to attach to the flagellum or the hook of other sperm, leading to the formation of sperm trains with enhanced swimming speed (Moore et al. 2002). Because of such a role, it was proposed that sperm competition would select for increased hook length and curvature and, indeed, comparative analyses found that species with relatively larger testes, have longer, more reflected apical sperm hooks (Immler et al. 2007). However, studies of interpopulation variation and differences between selection lines revealed that variation in the curvature of the hook is not explained by sperm competition (Firman \& Simmons 2009, 2011). Furthermore, although train formation has been found in other rodent species such as rat and mouse (Immler et al. 2007, Firman \& Simmons 2009) and Peromyscus (Fernandes et al. 2009, Fisher \& Hoekstra 2010) results are contradictory: trains do not swim faster than single sperm in the mouse (Immler et al. 2007), ejaculated sperm tend not to form trains in the mouse (Firman \& Simmons 2009) and trains are seen in both monogamous and promiscuous Peromyscus species (Fernandes et al. 2009, Fisher \& Hoekstra 2010). Finally, no direct link has been established between hook curvature and train formation. On the other hand, it is likely that sperm swim individually (and not in groups) once they move actively in the final leg of their journey towards the ova. Under such conditions, as suggested by our study, larger heads, with the presence of a hook, will further improve individual swimming speed, perhaps because such changes may make rodent sperm heads even more hydrodynamically efficient as sperm advance forward with a hatchet-like motion.

A second implication stems from the observation that sperm competition is associated with the area of the sperm head, because it could be argued that such increase in sperm head size may not be solely related to increases in swimming velocity. Additional explanations for larger heads associated with higher sperm 
competition levels may therefore be considered (Roldan et al. 1992). Among the series of processes that spermatozoa need to undergo to reach the site of fertilisation, an important step relates to an association with the epithelial cells lining the lower isthmus of the oviduct (Suarez 1998, 2008). If the sperm cells are to survive in this region they need to attach to the oviductal wall because those that do not die (Smith \& Yanagimachi 1990). The vast majority of sperm attaching to the wall have an intact acrosome (Esponda \& Moreno 1998). Thus, we propose that an increase in sperm head size may facilitate interactions and attachment with oviductal epithelial cells and that it may also obstruct the attachment of spermatozoa from rival males.

In summary, sperm competition in muroid rodents appears to lead to increases in sperm velocity that are related to longer spermatozoa. However, the earliest change brought about by sperm competition is related to increases in sperm head dimensions (area) in part caused by changes in the design of the sperm head (i.e. appearance of an apical hook). Although this results in an increase in sperm velocity, it may also be advantageous for sperm attachment to the oviductal wall to ensure sperm survival during the period of quiescence and final preparation for fertilisation.

\section{Materials and Methods}

Adult males from 11 species of muroid rodents were examined (three to five individuals for each species). Arvicola sapidus, Chionomys nivalis, Clethrionomys (Myodes) glareolus, Microtus arvalis, Microtus cabrerae, Microtus duodecimcostatus, Microtus lusitanicus and Apodemus sylvaticus were trapped in the field during the breeding season. Mus musculus, Mus spicilegus and Mus spretus were acquired from the Institut des Sciences de l'Evolution, CNRS-Université Montpellier 2, France. Individuals of these species were originally trapped in the field and kept in captivity for only a few generations.

Males were kept in individual cages, at $20-24^{\circ} \mathrm{C}$ and with a $14 \mathrm{~h}$ light:10 $\mathrm{h}$ darkness photoperiod, and provided with food and water ad libitum. Animal handling was done following Spanish Animal Protection Regulation RD1201/2005, which conforms to European Union Regulation 2003/65.

\section{Sperm analyses}

Males were killed by cervical dislocation and weighed. Testes were dissected out and weighed. Mature spermatozoa were collected from both epididymides and vasa deferentia and suspended in a Hepes-buffered modified Tyrode's medium as described (Shi \& Roldan 1995). Spermatozoa were allowed to swim out into the medium and sperm suspensions were used for assessments of sperm dimensions and sperm velocity parameters.

Sperm dimensions were assessed in sperm smears stained with Giemsa. Smears were examined at $1000 \times$ under bright field: images of 30 cells per male were captured using a digital camera (Digital Sight DS-5M, Nikon, Tokyo, Japan) and image software for microscopy (NIS-Elements F v.2.20, Nikon). Sperm dimensions were obtained for each sperm cell using ImageJ v.1.41 Software (National Institutes of Health, Bethesda, MD, USA) and included $\mathrm{HL}, \mathrm{HW}, \mathrm{HA}$ (including the apical hook when present), MPL, PPL+TPL, TFL and TSL. Ratios between dimensions of the various sperm components were calculated (i.e. HL/HW, HL/MPL, HL/PPL + TPL, HL/TFL, MPL/PPL + TPL and $\mathrm{HA} / \mathrm{TFL}$ ). In addition to the ratio $\mathrm{HL} / \mathrm{HW}$, which is an indicator of sperm elongation, an additional measure of elongation was also calculated $(\mathrm{HL}-\mathrm{HW}) /(\mathrm{HL}+\mathrm{HW})$.

Sperm velocity parameters were assessed using a computerassisted sperm analyser (Sperm Class Analyzer v.4.0, Microptic, Barcelona, Spain). The sperm suspension ( $6 \mu \mathrm{l})$ was placed in a $20 \mu \mathrm{m}$ deep slide chamber (Standard Count-2 Chamber Slide 20-micron, Leja, Nieuw-Vennep, The Netherlands) prewarmed to and kept at $37^{\circ} \mathrm{C}$, and examined using phase contrast optics and a $4 \times$ objective. Using a video camera (Basler A312fc, Vision Technologies, Glen Burnie, MD, USA) six videos of $4 \mathrm{~s}$ each were recorded for each male's sperm sample. Sperm concentration was adjusted to $4-6 \times 10^{6}$ sperm $/ \mathrm{ml}$ to satisfy the requirements of the system. Videos were analysed and a minimum of 150 tracks was obtained per sample. For each track six sperm velocity parameters were obtained: VCL (in $\mu \mathrm{m} / \mathrm{s}$ ), VAP (in $\mu \mathrm{m} / \mathrm{s}$ ), VSL (in $\mu \mathrm{m} / \mathrm{s}$ ), LIN (in $\%$ ), ALH (in $\mu \mathrm{m} / \mathrm{s}$ ) and BCF (in $\mathrm{Hz}$ ). We also recorded the VCL and VSL from the fastest spermatozoon for each sample (VCLmax and VSLmax respectively).

\section{Statistical and phylogenetic analyses}

To compare variability of sperm dimensions and sperm velocity components across species, CV were calculated as follows: $\mathrm{CV}=($ S.D. $\times 100) / \bar{x}$, where $\bar{x}=$ mean. Variables were transformed to attain normal distributions. Normal distribution was tested by a Kolmogorov-Smirnov normality test.

Relationships between body mass and sperm dimensions were tested by regression analysis in search of possible effects of allometry.

A global measure of sperm velocity (overall sperm velocity) was obtained by means of a PCA to reduce potentially correlated components of velocity $(\mathrm{VCL}, \mathrm{VAP}, \mathrm{VSL}, \mathrm{LIN}, \mathrm{ALH}$ and $\mathrm{BCF}$ ) to a single variable that would summarise the original information. This analysis extracted the first and second eigenvectors that summarised multivariate velocity variation and the best represented 'velocity components'.

To test whether different levels of sperm competition were associated with sperm velocity and dimensions across species, multiple regression analyses were performed by velocity parameters and sperm dimensions or ratios as dependent variables. Body mass and testes mass were used as predictor variables. Since predictor variables were related to each other (thus non-orthogonal), they were added to the multiple regression analysis in the following order: body mass, testes mass, using a sequential (type I) sum of squares.

To test whether sperm dimensions were associated with sperm velocity across species, we performed simple regression analysis, this time using velocity parameters as dependent variables and sperm dimensions (and ratios) as predictor 
variables. Associations between dimensions of the various sperm components were also examined.

Regression analyses were performed by a GLS approach in a phylogenetic framework (Freckleton et al. 2002) to control for phylogenetic effect on the associations of the variables, since species may share character values as a result of a common ancestry rather than independent evolution (Harvey \& Pagel 1991). GLS method allows for a variable degree of phylogenetic correction according to each tested model, accounting for different levels of phylogenetic association between different traits, and estimates a phylogenetic scaling parameter lambda $(\lambda)$, that represents the transformation that makes the data fit the Brownian motion evolutionary model. When $\lambda$ values are close to 0 , variables are likely to have evolved independently of phylogeny, whereas $\lambda$ values close to 1 indicate that the variables are strongly phylogenetically associated. The estimation of $\lambda$ values and GLS analyses were performed by a code written by $\mathrm{R}$ Freckleton for the statistical package R v.2.10.1 (R Foundation for Statistical Computing 2010) and the maximum likelihood value of $\lambda$ was compared against the models with $\lambda=0$ and $\lambda=1$.

Phylogenetic effects were controlled using a subset of a phylogenetic tree (Gómez Montoto et al. 2011) reconstructed based on several mitochondrial, nuclear and ribosomal genes (Martin et al. 2000, Lundrigan et al. 2002, Jaarola et al. 2004, Pfunder et al. 2004, Suzuki et al. 2004, Robovsky et al. 2008, Tougard et al. 2008, Bannikova et al. 2010).

All statistical analyses were conducted with R v.2.10.1 and SPSS v.17.0 (SPSS Inc., Chicago, IL, USA), and $P$ values were considered statistically significant at $\alpha<0.05$.

Finally, to plot results in various figures we calculated relative testes mass for each species using Kenagy \& Trombulak (1986) formula for rodents. Nevertheless, relative testes mass was not used in statistical analyses because this measure does not properly account for the allometric relationships between the variables (Tomkins \& Simmons 2002).

\section{Declaration of interest}

The authors declare that there is no conflict of interest that could be perceived as prejudicing the impartiality of the research reported.

\section{Funding}

This work was supported by the Spanish Ministry of Science and Innovation. L Gómez Montoto and J Martín-Coello were supported by predoctoral studentships from the Spanish Ministry of Education and Science. M Tourmente is a postdoctoral researcher funded by the Programa Nacional de Movilidad de Recursos Humanos de Investigación of the Spanish Ministry of Education.

\section{Acknowledgements}

We are grateful to $\mathrm{F}$ Bonhomme and A Orth (Institut des Sciences de I'Evolution, CNRS-Université Montpellier 2) who facilitated the acquisition of wild mice, and the Comunidad de Madrid and Junta de Castilla-León for permission to capture animals in the field. We thank Leticia Arroyo and Ana Piñeiro for help with fieldwork, José Benavent-Corai for help with laboratory analyses and F Couso-Ferrer for support with phylogenetic tree reconstruction.

\section{References}

Anderson MJ \& Dixson AF 2002 Sperm competition - motility and the midpiece in primates. Nature 416 496. (doi:10.1038/416496a)

Anderson MJ, Nyholt J \& Dixson A 2005 Sperm competition and the evolution of sperm midpiece volume in mammals. Journal of Zoology 267 135-142. (doi:10.1017/S0952836905007284)

Bannikova AA, Lebedev VS, Lissovsky AA, Matrosova V, Abramson NI, Obolenskaya EV \& Tesakov AS 2010 Molecular phylogeny and evolution of the Asian lineage of vole genus Microtus (Rodentia: Arvicolinae) inferred from mitochondrial cytochrome $b$ sequence. Biological Journal of the Linnean Society 99 595-613. (doi:10.1111/j.1095-8312. 2009.01378.x)

Birkhead TR \& Møller AP 1992 Sperm Competition in Birds: Evolutionary Causes and Consequences. London: Academic Press.

Birkhead TR, Martinez JG, Burke T \& Froman DP 1999 Sperm mobility determines the outcome of sperm competition in the domestic fowl. Proceedings of the Royal Society of London. Series B 266 1759-1764. (doi:10.1098/rspb.1999.0843)

Birkhead TR, Hosken DJ \& Pitnick S 2009 Sperm Biology. An Evolutionary Perspective. Burlington, MA: Academic Press.

Breed WG \& Taylor J 2000 Body mass, testes mass, and sperm size in murine rodents. Journal of Mammalogy 81 758-768. (doi:10.1644/15451542(2000)081 < 0758:BMTMAS > 2.3.CO;2)

Cassinello J, Abaigar T, Gomendio M \& Roldan ERS 1998 Characteristics of the semen of three endangered species of gazelles (Gazella dama mhorr, G. dorcas neglecta and G. cuvieri). Journal of Reproduction and Fertility 113 35-45. (doi:10.1530/jrf.0.1130035)

Cooper TG 2007 Sperm maturation in the epididymis: a new look at an old problem. Asian Journal of Andrology 9 533-539. (doi:10.1111/j.17457262.2007.00285.x)

Cummins JM \& Yanagimachi R 1982 Sperm-egg ratios and the site of the acrosome reaction during in vivo fertilization in the hamster. Gamete Research 5 239-256. (doi:10.1002/mrd.1120050304)

Cummins JM \& Woodall PF 1985 On mammalian sperm dimensions. Journal of Reproduction and Fertility 75 153-175. (doi:10.1530/jrf.0. 0750153)

Ding X, Leigh CM, Goodman SM, Bedford JM, Carleton MD \& Breed WG 2010 Sperm morphology in the Malagasy rodents (Muroidea: Nesomyinae). Journal of Morphology 271 1493-1500. (doi:10.1002/jmor.10889)

Esponda P \& Moreno M 1998 Acrosomal status of mouse spermatozoa in the oviductal isthmus. Journal of Experimental Zoology 282 360-366. (doi:10.1002/(SICI)1097-010X(19981015)282:3 <360::AID-JEZ8>3.3. $\mathrm{CO} ; 2-3)$

Fernandes PR, Tribble D, Dewey M, Crossland J \& Szalai G 2009 Analysis of interspecific sperm competition and aggregation in Peromyscus. Proceedings of the American Society of Mammalogists, 89th Annual Meeting, Fairbanks, AK, USA. Abstract.

Firman RC \& Simmons LW 2009 Sperm competition and the evolution of the sperm hook in house mice. Journal of Evolutionary Biology 22 2505-2511. (doi:10.1111/j.1420-9101.2009.01867.x)

Firman RC \& Simmons LW 2011 Sperm competition does not influence sperm hook morphology in selection lines of house mice. Journal of Evolutionary Biology 24 856-862. (doi:10.1111/j.1420-9101.2010. 02219.x)

Fisher HS \& Hoekstra HE 2010 Competition drives cooperation among closely related sperm of deer mice. Nature 463 801-803. (doi:10.1038/ nature08736)

Fitzpatrick JL, Montgomerie R, Desjardins JK, Stiver KA, Kolm N \& Balshine S 2009 Female promiscuity promotes the evolution of faster sperm in cichlid fishes. PNAS 106 1128-1132. (doi:10.1073/pnas. 0809990106)

Fitzpatrick JL, Garcia-Gonzalez F \& Evans JP 2010 Linking sperm length and velocity: the importance of intramale variation. Biology Letters 6 797-799. (doi:10.1098/rsbl.2010.0231) 
Florman HM \& Ducibella T 2006 Fertilization in mammals. In Knobil and Neill's Physiology of Reproduction, pp 55-112. Ed. JD Neill. San Diego: Elsevier.

Freckleton RP, Harvey PH \& Pagel M 2002 Phylogenetic analysis and comparative data: a test and review of evidence. American Naturalist 160 712-726. (doi:10.1086/343873)

Froman DP, Feltmann AJ, Rhoads ML \& Kirby JD 1999 Sperm mobility: a primary determinant of fertility in the domestic fowl (Gallus domesticus). Biology of Reproduction 61 400-405. (doi:10.1095/ biolreprod61.2.400)

Gage MJG 1998 Mammalian sperm morphometry. Proceedings of the Royal Society of London. Series B 265 97-103. (doi:10.1098/rspb.1998.0269)

Gage MJG, Stockley P \& Parker GA 1998 Sperm morphometry in the Atlantic salmon. Journal of Fish Biology 53 835-840. (doi:10.1111/j. 1095-8649.1998.tb01836.x)

Gage MJG, Macfarlane C, Yeates S, Shackleton R \& Parker GA 2002 Relationships between sperm morphometry and sperm motility in the Atlantic salmon. Journal of Fish Biology 61 1528-1539. (doi:10.1111/j. 1095-8649.2002.tb02495.x)

Gage MJG, Macfarlane CP, Yeates S, Ward RG, Searle JB \& Parker GA 2004 Spermatozoal traits and sperm competition in Atlantic salmon: relative sperm velocity is the primary determinant of fertilization success. Current Biology 14 44-47. (doi:10.1016/j.cub.2003.12.028)

Gasparini C, Simmons LW, Beveridge M \& Evans JP 2010 Sperm swimming velocity predicts competitive fertilization success in the green swordtail Xiphophorus helleri. PLoS ONE 5 e12146. (doi:10.1371/journal.pone. 0012146)

Gillies EA, Cannon RA, Green RB \& Pacey AA 2009 Hydrodynamic propulsion of human sperm. Journal of Fluid Mechanics 625 444-473. (doi:10.1017/S0022112008005685)

Gomendio M \& Roldan ERS 1991 Sperm competition influences sperm size in mammals. Proceedings of the Royal Society of London. Series B $\mathbf{2 4 3}$ 181-185. (doi:10.1098/rspb.1991.0029)

Gomendio M \& Roldan ERS 2008 Implications of diversity in sperm size and function for sperm competition and fertility. International Journal of Developmental Biology 52 439-447. (doi:10.1387/ijdb. 082595mg)

Gomendio M, Harcourt AH \& Roldan ERS 1998 Sperm competition in mammals. In Sperm Competition and Sexual Selection, pp 667-755. Eds TR Birkhead\& AP Møller. San Diego: Academic Press.

Gomendio M, Malo AF, Garde J \& Roldan ERS 2007 Sperm traits and male fertility in natural populations. Reproduction 134 19-29. (doi:10.1530/ REP-07-0143)

Gomendio M, Tourmente M \& Roldan ERS 2011 Why mammalian lineages respond differently to sexual selection: metabolic rate constrains the evolution of sperm size. Proceedings of the Royal Society of London. Series B 278 3135-3141. (doi:10.1098/rspb.2011.0275)

Gómez Montoto L, Magaña C, Tourmente M, Martín-Coello J, Crespo C, Luque-Larena JJ, Gomendio M \& Roldan ERS 2011 Sperm competition, sperm numbers and sperm quality in muroid rodents. PLOS ONE 6 e18173. (doi:10.1371/journal.pone.0018173)

Harcourt AH, Harvey PH, Larson SG \& Short RV 1981 Testis weight, bodyweight and breeding system in primates. Nature 293 55-57. (doi:10. 1038/293055a0)

Harvey PH \& Pagel MD 1991 The Comparative Method in Evolutionary Biology. Oxford: Oxford University Press.

Humphries S, Evans JP \& Simmons LW 2008 Sperm competition: linking form to function. BMC Evolutionary Biology 8 319-329. (doi:10.1186/ 1471-2148-8-319)

Immler S, Moore HDM, Breed WG \& Birkhead TR 2007 By hook or by crook? Morphometry, competition and cooperation in rodent sperm PLoS ONE 2 e170. (doi:10.1371/journal.pone.0000170)

Jaarola M, Martinkova N, Gunduz I, Brunhoff C \& Zima J 2004 Molecular phylogeny of the speciose vole genus Microtus (Arvicolinae, Rodentia) inferred from mitochondrial DNA sequences. Molecular Phylogenetics and Evolution 33 647-663. (doi:10.1016/j.ympev.2004. 07.015)

Jennions MD \& Passmore NI 1993 Sperm competition in frogs: testis size and a "sterile male" experiment on Chiromantis xerampelina (Rhacophoridae). Biological Journal of the Linnean Society 50 211-220. (doi:10.1006/bijl.1993.1055)
Kenagy GJ \& Trombulak SC 1986 Size and function of mammalian testes in relation to body size. Journal of Mammalogy 67 1-22. (doi:10.2307/ 1380997)

LaMunyon CW \& Ward S 1998 Larger sperm outcompete smaller sperm in the nematode Caenorhabditis elegans. Proceedings of the Royal Society of London. Series B 265 1997-2002. (doi:10.1098/rspb.1998. 0531)

Levitan DR 2000 Sperm velocity and longevity trade off each other and influence fertilization in the sea urchin Lytechinus variegatus. Proceedings of the Royal Society of London. Series B 267 531-534. (doi:10.1098/rspb.2000.1032)

Lundrigan BL, Jansa SA \& Tucker PK 2002 Phylogenetic relationships in the genus Mus, based on paternally, maternally, and biparentally inherited characters. Systematic Biology 51 410-431. (doi:10.1080/ 10635150290069878)

Lüpold S, Calhim S, Immler S \& Birkhead TR 2009 Sperm morphology and sperm velocity in passerine birds. Proceedings of the Royal Society of London. Series B 276 1175-1181. (doi:10.1098/rspb.2008.1645)

Malo AF, Garde JJ, Soler AJ, Garcia AJ, Gomendio M \& Roldan ERS 2005 Male fertility in natural populations of red deer is determined by sperm velocity and the proportion of normal spermatozoa. Biology of Reproduction 72 822-829. (doi:10.1095/biolreprod.104.036368)

Malo AF, Gomendio M, Garde J, Lang-Lenton B, Soler AJ \& Roldan ERS 2006 Sperm design and sperm function. Biology Letters 2 246-249. (doi:10.1098/rsbl.2006.0449)

Martin Y, Gerlach G, Schlotterer C \& Meyer A 2000 Molecular phylogeny of European muroid rodents based on complete cytochrome $b$ sequences. Molecular Phylogenetics and Evolution 16 37-47. (doi:10. 1006/mpev.1999.0760)

Miki K, Qu W, Goulding EH, Willis WD, Bunch DO, Strader LF, Perreault SD, Eddy EM \& O'Brien DA 2004 Glyceraldehyde 3-phosphate dehydrogenase-S, a sperm-specific glycolytic enzyme, is required for sperm motility and male fertility. PNAS 101 16501-16506. (doi:10.1073/pnas.0407708101)

Moore H, Dvoráková K, Jenkins N \& Breed W 2002 Exceptional sperm cooperation in the wood mouse. Nature 418 174-177. (doi:10.1038/ nature00832)

Parker GA 1970 Sperm competition and its evolutionary consequences in insects. Biological Reviews 45 525-567. (doi:10.1111/j.1469-185X. 1970.tb01176.x)

Pfunder M, Holzgang O \& Frey JE 2004 Development of microarray-based diagnostics of voles and shrews for use in biodiversity monitoring studies, and evaluation of mitochondrial cytochrome oxidase I vs. cytochrome $b$ as genetic markers. Molecular Ecology 13 1277-1286. (doi:10.1111/j. 1365-294X.2004.02126.x)

Robovsky J, Ricankova V \& Zrzavy J 2008 Phylogeny of Arvicolinae (Mammalia, Cricetidae): utility of morphological and molecular data sets in a recently radiating clade. Zoologica Scripta 37 571-590. (doi:10. 1111/j.1463-6409.2008.00342.x)

Roldan ERS, Gomendio M \& Vitullo AD 1992 The evolution of Eutherian spermatozoa and underlying selective forces - female selection and sperm competition. Biological Reviews 67 551-593. (doi:10.1111/j. 1469-185X.1992.tb01193.x)

Shi QX \& Roldan ERS 1995 Bicarbonate/ $/ \mathrm{CO}_{2}$ is not required for zona pellucida- or progesterone-induced acrosomal exocytosis of mouse spermatozoa but is essential for capacitation. Biology of Reproduction $\mathbf{5 2}$ 540-546. (doi:10.1095/biolreprod52.3.540)

Simmons LW 2001 Sperm Competition and its Evolutionary Consequences in Insects. Princeton: Princeton University Press.

Smith TT \& Yanagimachi R 1990 The viability of hamster spermatozoa stored in the isthmus of the oviduct: the importance of sperm-epithelium contact for sperm survival. Biology of Reproduction 42 450-457. (doi:10.1095/biolreprod42.3.450)

Soulsbury CD 2010 Genetic patterns of paternity and testes size in mammals. PLoS ONE 5 A152-A157. (doi:10.1371/journal.pone. 0009581)

Stockley P, Gage MJG, Parker GA \& Moller AP 1997 Sperm competition in fishes: the evolution of testis size and ejaculate characteristics. American Naturalist 149 933-954. (doi:10.1086/286031)

Suarez SS 1998 The oviductal sperm reservoir in mammals: mechanisms of formation. Biology of Reproduction 58 1105-1107. (doi:10.1095/ biolreprod58.5.1105) 
Suarez SS 2008 Regulation of sperm storage and movement in the mammalian oviduct. International Journal of Developmental Biology 52 455-462. (doi:10.1387/ijdb.072527ss)

Suzuki H, Shimada T, Terashima M, Tsuchiya K \& Aplin K 2004 Temporal, spatial, and ecological modes of evolution of Eurasian Mus based on mitochondrial and nuclear gene sequences. Molecular Phylogenetics and Evolution 33 626-646. (doi:10.1016/j.ympev.2004. 08.003)

Tomkins JL \& Simmons LW 2002 Measuring relative investment: a case study of testes investment in species with alternative male reproductive tactics. Animal Behaviour 63 1009-1016. (doi:10.1006/ anbe.2001.1994)

Tougard C, Brunet-Lecomte P, Fabre M \& Montuire S 2008 Evolutionary history of two allopatric Terricola species (Arvicolinae, Rodentia) from molecular, morphological, and palaeontological data. Biological Journal of the Linnean Society 93 309-323. (doi:10.1111/j.1095-8312. 2007.00926.x)
Tourmente M, Gomendio M, Roldan ERS, Giojalas L \& Chiaraviglio M 2009 Sperm competition and reproductive mode influence sperm dimensions and structure among snakes. Evolution 63 2513-2524. (doi:10.1111/j. 1558-5646.2009.00739.x)

Tourmente M, Gomendio M \& Roldan ERS 2011 a Sperm competition and the evolution of sperm design in mammals. BMC Evolutionary Biology 11 12. (doi:10.1186/1471-2148-11-12)

Tourmente M, Gomendio M \& Roldan ERS $2011 b$ Mass-specific metabolic rate and sperm competition determine sperm size in marsupial mammals. PLoS ONE 6 e21244. (doi:10.1371/journal.pone.0021244)

Received 28 June 2011

First decision 27 July 2011

Revised manuscript received 19 September 2011

Accepted 26 September 2011 